tumorigenesis. Thus, whereas c-Myc and Ras individually stimulate rRNA synthesis and cell-cycle progression, both activities together would be highly synergistic in activating cell division and cellular growth, the two processes essential for efficient proliferation.

The new reports on Myc demonstrate a key role for c-Myc in rRNA synthesis and, together with previous data, suggest that cMyc promotes growth in mammalian cells by enhancing ribosome biogenesis through the regulation of transcription by all three polymerases (Fig. 1). From a wider perspective, it shows that c-Myc controls both growth and cell division independently of each other. In other words, c-Myc alone may link and coordinate these two processes, which together determine cell size. However, this property is not limited to c-Myc because other important signalling pathways such as the Ras/MAPK and the phosphoinositide-3 kinase (PI3K) pathway also appear to acti- vate the cell cycle and growth machinery in an independent manner ${ }^{1}$ (Fig. 2).

The activity of these three tumour promoting pathways is known to be antagonized by strong tumour suppressor proteins, such as pRb, Arf and p53 which show the opposite behaviour, namely inhibition of cell division and repression of protein synthesis ${ }^{1,3}$. As outlined in Fig. 2, each of these six pathways simultaneously and independently controls cell division and cellular growth. All pathways affect growth and division at slightly different, potentially rate-limiting positions. Therefore, only the combination of different lesions might generate the strong synergy necessary to obtain the rapid mass increase that is observed in many cancers.

1. Sherr, C. J. Cell 116, 235-246 (2004).

2. Stocker, H. \& Hafen, E. Curr. Opin. Genet. Dev. 10, 529-535 (2000).

3. White, R.J Nature Rev. Mol. Cell Biol. 6, 69-78 (2005).

4. Grummt, I. Genes Dev. 17, 1691-1702 (2003).
5. Arabi, A. et al. Nature Cell Biol. 7, 302-309 (2005).

6. Grandori, C. et al. Nature Cell Biol. 7, 310-317 (2005).

7. Grewal, S.S., Li, L., Orian, A., Eisenman, R. N. \& Edgar, B. A. Nature Cell Biol. 7, 294-301 (2005).

8. Moss, T. Curr. Opin. Genet. Dev. 14, 210-217 (2004).

9. Levens, D. L. Genes Dev. 17, 1071-1077 (2003).

10. Grandori, C., Cowley, S. M., James, L.P. \& Eisenman, R. N. Annu. Rev. Cell Dev. Biol. 16, 653-699 (2000).

11. Wilson, A. et al. Genes Dev. 18, 2747-2763 (2004).

12. Johnston, L. A., Prober, D. A., Edgar, B. A., Eisenman, R. N. \& Gallant, P. Cel/ 98, 779-790 (1999).

13. Schuhmacher, M. et al. Curr. Biol. 9, 1255-1258 (1999).

14. Schlosser, I. et al. Nucleic Acids Res. 31, 6148-6156 (2003).

15. Poortinga, G. et al. EMBO J. 23, 3325-3335 (2004).

16. Eisenman, R. N. Genes Dev. 15, 2023-2030 (2001).

17. Frank, S. R. et al. EMBO Rep. 4, 575-580 (2003).

18. Arabi, A., Rustum, C., Hallberg, E. \& Wright, A.P. J. Cell Sci. 116, 1707-1717 (2003).

19. von der Lehr, N. et al. Mol. Cell 11, 1189-1200 (2003).

20. Kim, S. Y., Herbst, A., Tworkowski, K. A., Salghetti, S. E. \& Tansey, W.P. Mol. Cell 11, 1177-1188 (2003)

21. Welcker, M., Orian, A., Grim, J.A., Eisenman, R. N. \& Clurman, B. E. Curr. Biol. 14, 1852-1857 (2004).

22. Trumpp, A. et al. Nature 414, 768-773 (2001).

23. Zhao, J., Yuan, X., Frodin, M. \& Grummt, I. Mol. Cell 11, 405-413 (2003)

\section{Nucleolar targeting runs on GTP cycles}

A paper in the 17 January issue of the Journal of Cell Biology reports a new mechanism for localizing nucleolar proteins: GTP binding and hydrolysis. Many proteins reside in the nucleolus - the site of rRNA biogenesis - but comparatively little is known about how these proteins reach this site, what keeps them there or what causes them to depart. In their new study, Robert Tsai and Ronald McKay provide some answers (J. Cell Biol., doi: 10.1083/jcb.200409053; 2005).

Tsai and McKay focused on nucleostemin, a nucleolar GTP-binding protein that regulates cell proliferation. They observed that nucleostemin rapidly shuttles between the nucleolus and nucleoplasm, and so wanted to address how this cycling is controlled. They found that, rather than a simple case of a single sequence targeting the protein to the nucleolus, nucleostemin cycling is governed by multiple domains of the protein: a basic domain in the protein is necessary and sufficient for nucleolar targeting, but localization also requires GTP binding. Disrupting either domain led to increased dissociation of nucleostemin from the nucleolus. Two other domains are also needed to allow nucleostemin to subsequently dissociate from the nucleolus.

For many GTP-binding proteins, nucleotide binding triggers a switch in the protein's conformation and affects its activity and function. In the case of nucleostemin, the GTP cycle may alter the protein's conformation and so fully expose retention or dissociation motifs that lead to a switch in its binding affinity for the nucleolus.

It is not known whether nucleostemin acts in the nucleolus or the nucleoplasm; but given that nucleostemin is a growth regulator, the

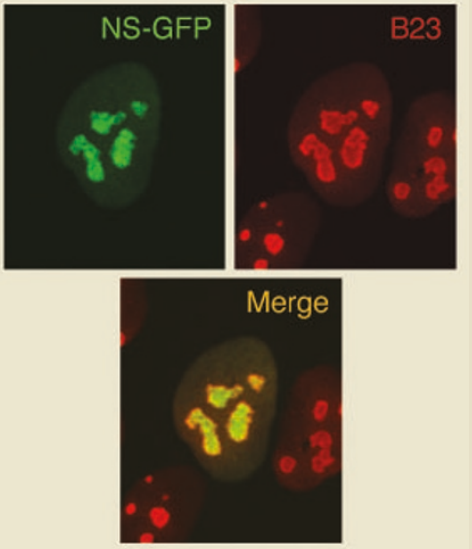

Cells expressing a nucleostemin-GFP fusion (green) and labelled with anti-B23 antibody (red) show localization of nucleostemin in the nucleolus.

GTP-regulated cycling of the protein between the nucleolus and the nucleoplasm might provide a means for signalling pathways to regulate localization of the protein, and hence its function.

Intriguingly, the nucleolar distribution of a non-GTP-binding protein, B23, is also sensitive to GTP levels, although the reason for this is unclear. One possibility is that its localization is controlled by a GTPbinding protein. Aside from nucleostemin and B23, it is not known whether the distribution of other nucleolar proteins is controlled by GTP concentrations, but it is nevertheless tempting to propose that GTP-binding proteins might direct nucleolar organization.

SOWMYA SWAMINATHAN 